\title{
TINJAUAN KEADAAN FASILITAS SANITASI OBYEK WISATA PURA TIRTA SUDAMALA KELURAHAN BEBALANG, KABUPATEN BANGLI TAHUN 2017
}

\section{Gede Agus Depantara1, I Made Bulda Mahayana²}

\begin{abstract}
Sanitation of public places is a disease prevention effort that focuses its activities on the cleanliness / health of public places (TTU) in serving the public in connection with the activities of the public places physiologically, psychologically, prevent the occurrence of disease or accidental transmission As well as aesthetics, inter-occupants, users, and the surrounding community. This research is a type of descriptive research with direct observation to the location and describes the condition of the location which includes the condition of waste facility, public toilet / toilet and canteen in accordance with the field. In this study used an observation sheet with different items. To know the state of sanitation facilities used two categories of assessment that is eligible and less qualified. The research was conducted in Pura Tirta Sudamala Banjar Sedit Bebalang Village, Bangli Sub-District, Bangli Regency using obervation technique. All items are 46 items. The results of the review of the condition of the sanitation facilities of the temple attractions tirta sudamala kelurahan bebalang, bangli regency eligible to get a score of 31 scores while not to meet the requirements of 15 scores, so the state of sanitary facilities in the temple tirta sudamala in the category qualify because the category of the state Eligible 0-23 and eligible categories 24-46.
\end{abstract}

Keywords : Sanitation, Tourism Object, Public places

Sanitasi merupakan bagian dari ilmu kesehatan lingkungan yang meliputi cara dan usaha individu atau masyarakat untuk mengontrol dan mengendalikan lingkungan hidup eksternal yang berbahaya bagi kesehatan serta yang dapat mengancam kelangsungan hidup manusia ${ }^{1}$ Kecenderungan itu merupakan pertanda tingginya permintaan akan agrowisata dan sekaligus membuka peluang bagi pengembangan produk-produk agrobisnis, baik dalam bentuk kawasan ataupun produk pertanian yang mempunyai daya tarik spesifik $^{2}$.

Sanitasi tempat-tempat umum adalah suatu usaha pencegahan penyakit yang menitikberatkan kegiatannya pada usaha-usaha kebersihan / kesehatan tempattempat umum (TTU) dalam melayani masyarakat umum sehubungan dengan aktivitas tempat-tempat umum tersebut secara fisiologis, psikologis, mencegah terjadinya penularan penyakit atau kecelakaan 
serta estetika, antar penghuni, pengguna, dan masyarakat sekitarnya ${ }^{3}$.

Sanitasi adalah upaya pengawasan faktor-faktor lingkungan fisik manusia yang mempunyai pengaruh terhadap perkembangan fisik manusia, kesehatan maupun kelangsungan hidupnya ${ }^{4}$. Daerah tujuan pariwisata yang selanjutnya disebut Destinasi Pariwisata adalah kawasan geografis yang berada dalam satu atau lebih wilayah administratif yang di dalamnya terdapat daya tarik wisata, fasilitas umum, fasilitas pariwisata, aksesibilitas, serta masyarakat yang saling terkait dan melengkapi terwujudnya kepariwisataan ${ }^{1}$.

Berdasarkan hasil observasi yang penulis lakukan pada Pura Tirta Sudamala Permasalahan yang di dapat yaitu belum adanya pemeriksaan tentang keadaan fasilitas sanitasi yakni pada fasilitas sanitasi di Pura Tirta Sudamala seperti : Keadaan pembuangan sampah, WC umum, dan kantin / warung sehingga penulis mengambil karya tulis dengan judul "Tinjauan Keadaan Fasilitas Sanitasi di Obyek Wisata Pura Tirta Sudamala,
Kelurahan Bebalang, Kabupaten Bangli Tahun $2017^{5}$.

Tujuan dari penelitian adalah untuk mengetahui Keadaan Fasilitas Sanitasi Obyek Wisata Pura Tirta Sudamala, Kelurahan Bebalang, Kabupaten Bangli : (1) Untuk mengetahui keadaan fasilitas Sanitasi Tempat Sampah di Obyek Wisata Pura Tirta Sudamala, Kelurahan Bebalang, Kabupaten Bangli ; (2) Untuk mengetahui keadaan fasilitas WC / toilet umum di Obyek Wisata Pura Tirta Sudamala, Kelurahan Bebalang, Kabupaten Bangli ; (3) Untuk mengetahui keadaan fasilitas kantin / warung di Obyek Wisata Pura Tirta Sudamala, Kelurahan Bebalang, Kabupaten Bangli ; (4) Untuk mengetahui keadaan sanitasi di Obyek Wisata Pura Tirta Sudamala, Kelurahan Bebalang, Kabupaten Bangli

\section{METODE}

Dalam penelitian ini penulis menggunakan jenis penelitian deskritif yaitu melakukan pengamatan langsung ke lokasi dan menggambarkan keadaan lokasi yang meliputi keadaan fasilitas tempat sampah, WC umum / toilet dan 
kantin sesuai dengan di lapangan. Penelitian ini tidak membutuhkan kelompok control dan hipotesis yang spesifik $^{6}$.

Lokasi penelitian ini di laksanakan di Obyek Wisata Pura Tirta Sudamala Kelurahan Bebalang, Kabupaten Bangli, pada bulan Februari 2017 sampai dengan bulan Juli 2017. Dalam penelitian ini jenis data yang di kumpulkan adalah data primer : merupakan data yang dikumpulkan oleh peneliti secara langsung melalui lembar observasi, yaitu dengan menilai keadaan fasilitas sanitasi yang ada di Obyek Wisata Pura Tirta Sudamala tersebut meliputikeadaan fasilitas tempat sampah, WC umum / toilet dan kantin. Data sekunder : Data sekunder merupakan data yang diambil dari suatu sumber yang diperoleh peneliti secara tidak langsung melalui media perantara (diperoleh dan dicatat pihak lain). Data sekunder dalam penelitian ini adalah data yang sudah jadi berasal dari kajian buku.
Teknik pengumpulan data di lakukan dengan cara : Penulis menggunakan lembar observasi keadaan sanitasi kawasan wisata dengan melakukan pengamatan sebanyak satu kali. Data yang diperoleh dari penelitian ini terlebih dahulu dikumpulkan kemudian data ditabulasikan dan dihitung lalu disajikan dalam bentuk tabel. Dalam penelitian ini dipergunakan lembar observasi dengan item yang berbedabeda.Untuk mengetahui keadaan fasilitas sanitasi digunakan dua katagori penilaian yaitu memenuhi syarat dan kurang memenuhi syarat. Setiap item akan diberi nilai dengan menggunakan interval kelas yang berpedoman pada rumus Sturgess Tiap item pada lembar observasi akan diberikan skor satu untuk menjawab "YA" dan skor nol untuk jawab "TIDAK"

Interval =

skor tinggi-skor terendah jumlah kelas 


\section{HASIL DAN PEMBAHASAN}

1. Fasilitas sanitasi tempat sampah

Tabel 1

Keadaan Fasilitas Sanitasi Tempat Sampah di Obyek Wisata Pura Tirta Sudamala, Kelurahan Bebalang, Kabupaten Bangli Tahun 2017

\begin{tabular}{lllll}
\hline \multirow{2}{*}{ NO JENIS ITEM YANG DI PERIKSA } & HASIL & \multirow{2}{*}{ SKOR } \\
& YA TIDAK & \\
\hline
\end{tabular}

A. Fasilitas Sanitasi Tempat Sampah

1 Tempat sampah kedap air dan udara

2 Tempat sampah ringan

3 Tempat sampah mudah di angkat

$4 \quad$ Tempat sampah tertutup

5 Tempat sampah tahan karat

6 Tempat sampah mudah dibersihkan

$7 \quad$ Tempat sampah mudah di peroleh

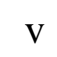

1 Pengumpulan dan pembuangan di

8 lakukan setiap hari secara rutin

9 Tempat sampah dibedakan warna, bahan, dan bentuk

Tempat pengumpulan sampah sementara

10 harus terletak di tempat yang mudah di V 0 jangkau oleh pengangkut sampah
SKOR 7
Berdasarkan tabel 2 menunjukkan keadaan fasilitas Sanitasi Tempat Sampah di Obyek Wisata Pura Tirta Sudamala, Kelurahan Bebalang, Kabupaten Bangli memenuhi syarat dengan skor 7.
2. Fasilitas Sanitasi WC umum / toilet

Keadaan Fasilitas Sanitasi WC umum / Toilet di Obyek Wisata Pura Tirta Sudamala, Kelurahan Bebalang, Kabupaten Bangli tidak 
memenuhi syarat dengan skor 14 karena tidak mempunyai setiptank.

3. Fasilitas Sanitasi Kantin

Keadaan Fasilitas Sanitasi Kantin di Obyek Wisata Pura Tirta Sudamala, Kelurahan Bebalang, Kabupaten Bangli memenuhi syarat (skor 12)

4. Fasilitas Sanitasi Pura Tirta Sudamala

Keadaan Fasilitas Sanitasi di Obyek Wisata Pura Tirta Sudamala, Kelurahan Bebalang, Kabupaten Bangli memenuhi syarat (skor 33), Fasilitas Sanitasi Tempat Sampah memenuhi syarat (skor 7), Fasilitas Sanitasi Wc umum/toilet tidak memenuhi syarat (skor 14), Fasilitas Sanitasi Kantin memenuhi syarat (skor 12).

\section{PEMBAHASAN}

1. Fasilitas Tempat Sampah

Hasil penelitian menunjukkan bahwa tempat sampah yang tersedia di area Pura Tirta Sudamala sudah mencukupi dan tersebar di beberapa titik yang mudah untuk di peroleh oleh pengunjung. Tempat sampah tidak di bedakan berdasarkan warna, bahan, dan bentuk yang bertujuan untuk mempermudah dalam pemilahan sampah. Pengumpulan dan pembuangan belum di lakukan setiap hari secara rutin. Karena penumpukan volume sampah hanya terjadi di hari-hari tertentu. Tempat pengumpulan sampah sementara tidak tersedia, karena sampah yang di hasilkan langsung di buang ke kebun atau langsung ke badan air.

2. Fasilitas WC Umum / toilet

Pada fasilitas wc umum / toilet di Pura Tirta Sudamala sudah tersedia dua jamban untuk pengunjung, dimana jamban tersebut sudah di pisahkan antara pengunjung laki-laki dan perempuan. Wc umum / toilet di tirta sudamala air bersih sudah mencukupi, lantai tidak licin, kedap air, mudah di bersihkan, tidak terjadi genangan air dan tersedianya tempat sampah. Berdasarkan hasil wawancara dengan pengelola Pura Tirta Sudamala Wc umum / toilet masih belum memiliki setiptank. Karena Pura Tirta Sudamala terletak di aliran sungai sehingga kekurangan lahan untuk membuat sepictank maka dari itu limbah dari wc di alirkan langsung ke sungai. Tidak tesedia sabun dan alat pengering di area wc umum/toilet. 


\section{Fasilitas Sanitasi Kantin}

Untuk sanitasi kantin di Pura Tirta

Sudamala makanan dan minuman sudah tertutup dan terbebas dari lalat, lantai kantin mudah di bersihkan, kedap air dan tersedia tempat sampah di setiap kantin. Pedagang tidak menderita penyakit menular (diare) pedagang berpakaian bersih, kuku bersih dan pendek. Namun kebanyakan pedagang belum menggunakan celemek untuk menjaga kebersihan makanan yang di sajikan dan beberapa kantin, masih belum memiliki bak tempat mencuci peralatan nya karena keperluan air mengalir sudah mencukupi. Pedagang juga tidak menggunakan penutup kepala/rambut, makanan jadi dan bahan makanan tidak terpisah atau di campur. Penjamah makanan menggunakan cicin saat mengolah makanan yang dapat menkontaminasi makanan yang di sajikan nya. Pemisahan bahan makanan dengan makanan jadi sangat penting, karena dapat meminimalisir terkontaminasinya makanan. Semua pedagang tidak memiliki surat keterangan sehat. Lokasi untuk mendirikan tempat pengelolaan makanan seperti rumah makan dan jasa boga lainnya merupakan suatu langkah awal yang penting dalam menentukan kualitas makanan yang akan di konsumsi oleh masyarakat. Jarak pengelolaan jasa boga harus jauh dari sumber pencemaran seperti sampah umum, WC umum, kantin dan sumber pencemaran lain.

\section{Fasilitas Sanitasi Pura Tirta Sudamala}

Fasilitas sanitasi yang tersedia di Pura Tirta Sudamala sudah memenuhi syarat seperti tempat sampah yang memadai namun belum di pergunakan dengan baik dan pengangkutan sampah masih belum teratur. Wc umum / toilet yang bersih namun jumlah wc yang masih kurang karena masih terbentur dengan tempat dan masih dalam tahap pembangunan. Kantin yang tertata rapi dan di jaga kebersihan nya dengan di sediakan nya tempat sampah di setiap kantin namun dalam menyajikan makanan pedagang masih banyak yang belum menggunakan celemek untuk menjaga kebersihan makanan ${ }^{7}$. Menurut Keputusan Menteri Kesehatan Republik Indonesia 


\section{NO/288/MENKES/SK/III/2003}

tentang pedoman penyehatan sarana dan bangunan umum dalam rangka memfasilitasi penyelenggaraan otonomi daerah telah diterbitkan beberapa Keputusan Menteri Kesehatan yang berkaitan dengan kesehatan lingkungan pada sarana dan bangunan umum, di antaranya tentang penyehatan hotel, rumah sakit, perumahan dan lingkungan kerja $^{8}$. Bahwa prasarana harus tersedia untuk kawasan pariwisata seperti tong sampah yang lengkap sesuai jenis sampah yang dihasilkan dan disediakan di tempat-tempat yang strategi sehingga tidak menganggu kenyamanan pengunjung.

\section{SIMPULAN DAN SARAN}

Simpulan dari penelitian ini adalah (1) Fasilitas Sanitasi Tempat Sampah di Obyek Wisata Pura Tirta Sudamala, Kelurahan Bebalang, Kabupaten Bangli memenuhi syarat Fasilitas Sanitasi Tempat Sampah dengan skor 7. (2) Fasilitas Sanitasi WC umum / Toilet di Obyek Wisata Pura Tirta Sudamala, Kelurahan Bebalang, Kabupaten Bangli tidak memenuhi syarat karena wc harus memiliki septictank, dengan skor 14 . (3) Fasilitas Sanitasi Kantin di Obyek Wisata Pura Tirta Sudamala, Kelurahan Bebalang, Kabupaten Bangli memenuhi syarat Fasilitas Sanitasi Kantin dengan skor 12. (4) Fasilitas Sanitasi di Obyek Wisata Pura Tirta Sudamala, Kelurahan Bebalang, Kabupaten Bangli memenuhi syarat Fasilitas Sanitasi sesuai dengan Keputusan Menteri Kesehatan Republik Indonesia NO/288/MENKES/SK/III/2003

dengan skor 33. Adapun saran yang dapat di sampaikan (kemenkes RI, 2003) (1) Bagi Pengelola Pura Tirta Sudamala Diharapakan agar segera melengkapi fasilitas sanitasi tempat sampah seperti membedakan warna, bahan dan bentuk sampah. Wc harus di lengkapi dengan setiptank untuk memenuhi persyaratan sanitasi yang baik sehinga derajat kesehatan terjaga dan terhindar dari penyakit berbasis lingkungan. (2) Bagi Pengunjung Diharapakan dapat ikut menjaga kebersihan, misalnya mempunyai sampah jangan dibuang sembarangan sebaiknya disimpan dulu disaku, kalau sudah menemukan tepat sampah yang disedikan dari petugas dari Pura Tirta Sudamala 
baru disana dibuang supaya Pura

Tirta Sudamala terjaga

kebersihannya dan kehindahan

alamnya. (3) Bagi Peneliti

Selanjutnya Dapat di jadikan bahan

tambahan referensi dan bahan

masukan untuk penelitian

selanjutnya yang terkait dengan penelitian ini.

1. Candra. Pengantar Kesehatan

Lingkunga. (Kedokteran EGC, 2007).

2. Malik. Strategi

Pengembangan Agrowosata.

(Fakultas Sains dan Teknologi

UNI Syarif Hidayatullah, 2010).

3. Suyono. Ilmu Kesehatan

Masyarakat. (Kedokteran

EGC, 2014).
4. Siswanto. Kamus Popules

Kesehatan Lingkungan.

(Kedokteran EGC, 2003).

5. Disbudpar. Wisata Spiritual

Tirta Sudamala. Disbudpar

Bangli (2017). Available at:

http://disbudpar.banglikab.go.i

d/. .

6. Arikunto. Prosedur Penelitian

Suatu Pendekatan Proposal.

(Bina Aksara, 2010).

7. Mukono. Prinsip Dasar

Kesehatan Lingkungan.

(Airlangga University, 2006).

8. Kemenkes. Pedoman

Penyehatan Sarana Dan

Bangunan Umum. (2003). 